\title{
Preparation of Silicon Nanoparticles by Pyrolysis of Organosilicon Compounds inside the Porous Carbon
}

\author{
Michiya Ota*, Kazunari Arai, Ayano Kuribara, Yonekazu Deguchi*, Kota Onozuka \\ Department of Chemistry and Materials Science, Gunma College, National Institute of Technology, Maebashi, Japan \\ Email:^ota@chem.gunma-ct.ac.jp, ^deguchi@chem.gunma-ct.ac.jp
}

How to cite this paper: Ota, M., Arai, K., Kuribara, A., Deguchi, Y. and Onozuka, K. (2020) Preparation of Silicon Nanoparticles by Pyrolysis of Organosilicon Compounds inside the Porous Carbon. Journal of Materials Science and Chemical Engineering, 8, 1-6.

https://doi.org/10.4236/msce.2020.82001

Received: December 8, 2019

Accepted: January 13, 2020

Published: January 16, 2020

Copyright $\odot 2020$ by author(s) and Scientific Research Publishing Inc. This work is licensed under the Creative Commons Attribution-NonCommercial International License (CC BY-NC 4.0). http://creativecommons.org/licenses/by-nc/4.0/ (c) (i) \& Open Access

\begin{abstract}
To increase the capacity of the negative electrode for lithium-ion secondary batteries, we prepared Si-containing carbon microspheres. The target compound was obtained by thermal decomposition of hexaphenyldisilane embedded in porous carbon particles that contained Si-nanoparticles characterized by various methods. When charging/discharging characteristics were evaluated using a cell having the obtained material as a negative electrode, a remarkable improvement in charging characteristics was observed.
\end{abstract}

\section{Keywords}

Lithium-Ion Secondary-Battery, Silicon Nanoparticles, Si-Containing Porous Carbon

\section{Introduction}

Negative electrodes with high energy densities are required for developing next generation energy-storage materials. Lithiation of silicon, aluminum, and stannum gives rise to large specific capacities: for instance, $\mathrm{Li}_{22} \mathrm{Si}_{5}: 4200 \mathrm{mAh} / \mathrm{g}$, AlLi: $993 \mathrm{mAh} / \mathrm{g}$ and $\mathrm{Li}_{22} \mathrm{Sn}_{5}: 994 \mathrm{mAh} / \mathrm{g}$ [1]-[10]. Although these compounds have large specific capacities, they also have shortages. For example, negative electrodes made of silicon exhibited large volume changes when lithium ions were adsorbed. Volume expansion of more than $200 \%-400 \%$ of the pristine silicon resulted in pulverization because of accumulated mechanical strain inside the crystal after repeated expansion and contraction [4] [5] [8] [9] [11]. Besides, silicon has been known for semiconducting nature. These properties caused the decrease in the rate and cycle characteristics. Previously, we have reported that 
silicon nanoparticle-containing porous carbon microspheres improved the cycle characteristics and specific discharged capacity [12]. However, average particle diameter of silicon nanoparticles was around $50 \mathrm{~nm}$ and as a result the effective rate of silicon to lithium exchange was not improved. Therefore, the aim of the present research is to prepare silicon nanoparticles with more or less $20 \mathrm{~nm}$ in diameter using pyrolysis of organosilicon compounds inside the porous carbon. Electrochemical properties such as charge-discharge behavior, cyclic characteristics will be described in this report.

\section{Experimental}

\subsection{Preparation of Porous Carbon}

Phenolic resin (1.5 g) spheres were swollen in a mixture of sulfuric acid and nitric acid for $12 \mathrm{~h}$ at $80^{\circ} \mathrm{C}$. Then, the mixed acid solution was added to $300 \mathrm{~mL}$ of water cooled in an ice bath, and the solution was stirred until sulfuric acid was homogeneously dissolved. After the exothermic heat dissipated, the aqueous solution was centrifuged ( $3000 \mathrm{rpm}, 10 \mathrm{~min}$ ), and the precipitates were collected. Porous carbon was prepared through a rapid pyrolysis of the precipitates at $1000^{\circ} \mathrm{C}$

\subsection{Preparation of Si-Containing Porous Carbon}

Hexaphenyldisilane was dissolved in $30 \mathrm{~mL}$ of THF, followed by the addition of $200 \mathrm{mg}$ of porous carbon and stirring for $12 \mathrm{~h}$. Then, THF was removed by heating under a reduced pressure. Thermal decomposition of the mixture was performed under $\mathrm{N}_{2}$ at $500^{\circ} \mathrm{C}$.

\subsection{Characterization of Si-Containing Porous Carbon}

The composition and structural analyses of silicon in the porous carbon particles were performed using a transmission electron microscopy (TEM), energy dispersive X-ray analysis (EDX), and X-ray diffractometry (XRD). Si-containing porous carbon was mixed with carbon black as a conductive additive, styrene-butadiene rubber as a binder, and carboxymethyl cellulose as a thickener in a mixing ratio of sample:conductive additive:(binder + thickener) $=8: 1: 1$, dispersed on a copper foil. Using this electrode a coin cell was constructed with 1 $\mathrm{mol} / \mathrm{L} \mathrm{LiBF}_{4} / \mathrm{ED}+\mathrm{DEC}(1 / 1, \mathrm{v} / \mathrm{v})$ as the electrolyte and Li foil as the counter electrode, and charge/discharge measurement was performed. Measurements were done at a current density of $100 \mathrm{~mA} / \mathrm{g}$ and a potential range of $0.01-2 \mathrm{~V}$ (vs. $\mathrm{Li} / \mathrm{Li}^{+}$).

\section{Results and Discussion}

\subsection{TEM Images of Si-Containing Porous Carbon}

Figure 1 shows the TEM images of Si-containing porous carbon: (a) Si-containing porous carbon, (b) magnified image of (a), (c) a single nanoparticle. 

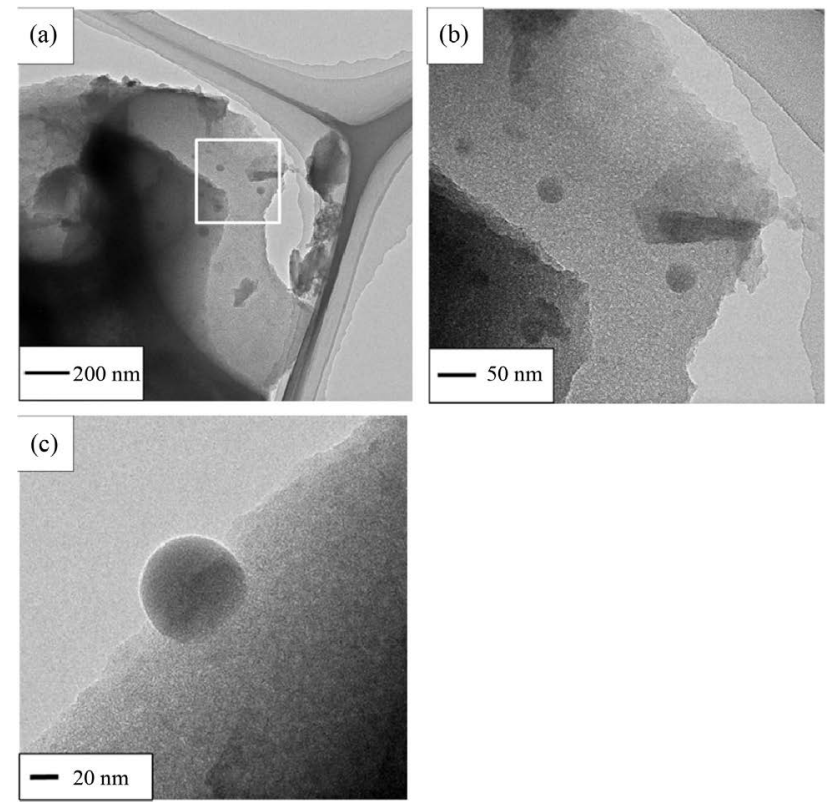

Figure 1. TEM images of Si-containing porous carbon: (a) Si-containing porous carbon, (b) magnified image of a rectangular area in the image (a), (c) nanoparticle.

TEM images of Si-containing porous carbon particle in Figure 1 show the formation of Si nanoparticles with less than $30 \mathrm{~nm}$ in diameter inside the porous carbon microparticle.

\subsection{EDX Measurement of Nanoparticle inside Porous Carbon}

Figure 2 shows EDX patterns and contents of a nanoparticle.

The EDX pattern of the nanoparticle showed that the elemental composition of $\mathrm{Si} / \mathrm{C}=0.06, \mathrm{O} / \mathrm{Si}=0.36$, and $\mathrm{O} / \mathrm{C}=0.02$. The result suggests that $\mathrm{Si}$ nanoparticle was possibly formed.

\subsection{XRD Measurement}

Figure 3 shows XRD patterns of (a) porous carbon and (b) Si-containing porous carbon.

Porous carbon (a) showed a broad diffraction band reminiscent of non-graphitizable carbon.

Si-containing porous carbon (b) showed a pattern similar to that of porous carbon.

No peaks assignable to $\mathrm{Si}$ or $\mathrm{SiC}$ were observed.

It is likely that this particle is made of amorphous carbon because of absence of crystalline peaks.

\subsection{Characterization of Charge/Discharge Behavior of Coin-Type Secondary Battery Assembled with Si-Containing Porous Carbon Particle}

Discharge and charge curves and cyclic behavior of Si-containing porous carbon 


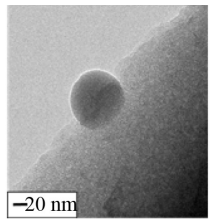

Full scale count 2975

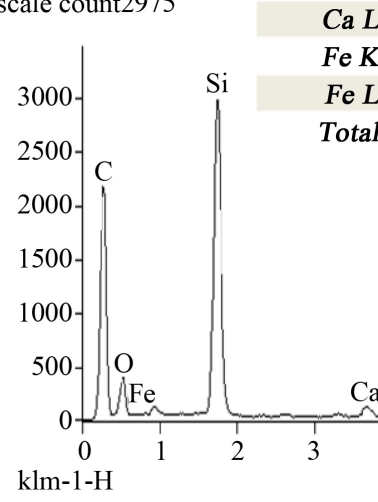

$\mathrm{Si}$

Ca

\section{Elements Net counts}

Concentration

(wt\%)

84.64

n

Atom concentration

CK 18231

\begin{tabular}{ll}
\hline O & 2838
\end{tabular}

SiK $\quad 30179$

2.54

11.59

1515

0

1577

380

0.54

$---$

0.68

100.00

tal

(1000

92.19

92.19

2.08

5.40

$---$

0.18

---

0.16

$---$

100.00

Figure 2. Elemental analysis of a nanoparticle in Figure 1(c) using EDX.

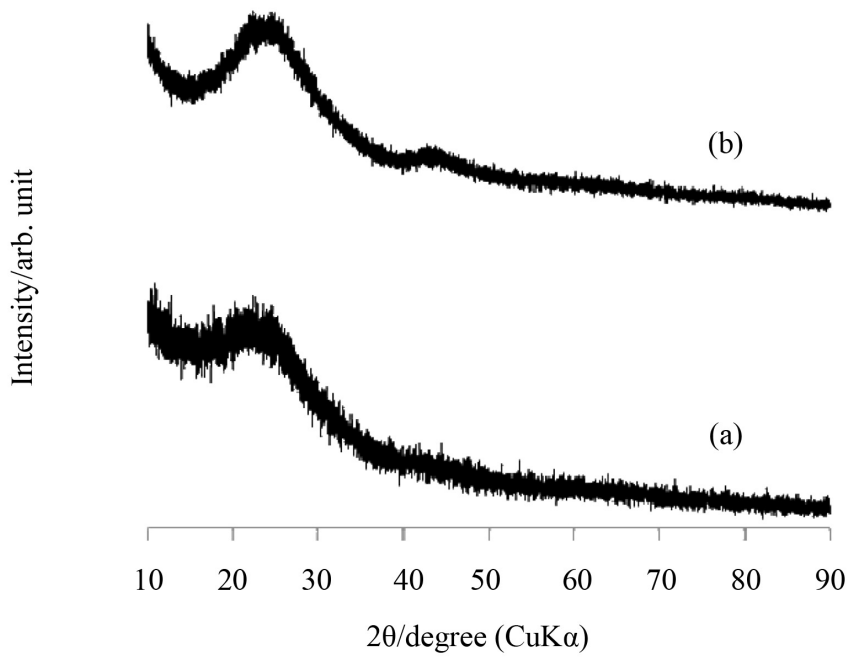

Figure 3. XRD patterns of (a) porous carbon and (b) Si-containing porous carbon.

cell were given in Figure 4 and Figure 5, respectively.

Figure 4 shows the irreversible capacity was observed with initial charge/discharge curve of Si-containing porous carbon cell.

Figure 5 shows the cycle characteristics of discharge capacity. The discharge capacity in the first cycle was high, but, in the second cycle, the discharge capacity largely de-creased.

Table 1 shows the effect of Si on the discharge capacities. Discharge capacity of the porous carbon cell was $22.5 \mathrm{mAh} / \mathrm{g}$, whereas, that of Si-containing porous carbon was $845 \mathrm{mAh} / \mathrm{g}$. The discharge capacity of the porous carbon cell after second cycle, subsequently, decreased up to $6.4 \mathrm{mAh} / \mathrm{g}$ and the decay was about $28 \%$. On the other hand, that of Si-containing porous carbon decreased up to 
$226 \mathrm{mAh} / \mathrm{g}$ with the decay of $27 \%$. Thus, this decrease in capacity can be attributed, not clear at the pre-sent time, to the generation of solid electrolyte interface (SEI), but the content of Si relatively would raise the discharge capacity, compared with that of porous carbon cell.

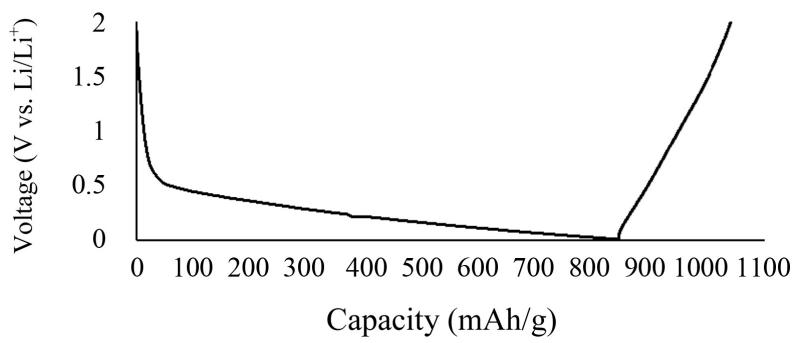

Figure 4. Discharge-charge curves of Si-containing porous carbon cell.

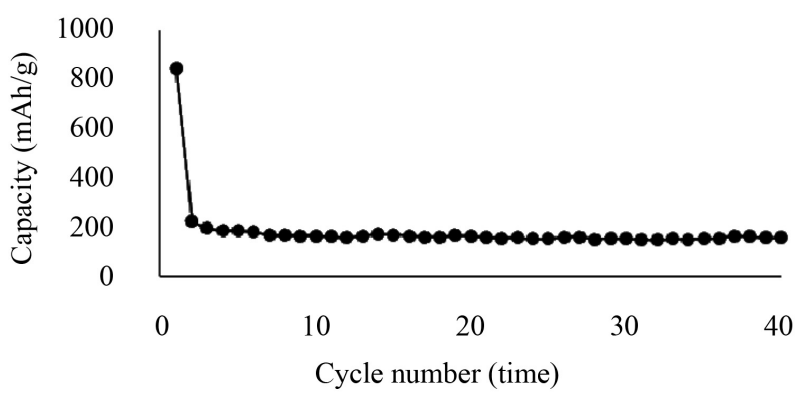

Figure 5. Cyclic behavior of Si-containing porous carbon cell.

Table 1. Discharge capacities after cycle performances.

\begin{tabular}{ccccc}
\hline Sample & $1^{\text {st }}$ cycle & $2^{\text {nd }}$ cycle & $10^{\text {th }}$ cycle & $40^{\text {th }}$ cycle \\
\hline Porous carbon & 22.5 & 6.4 & 6.1 & 9.2 \\
Si-containing porous carbon & 845 & 226 & 167 & 161 \\
\hline
\end{tabular}

\section{Conclusion}

Silicon nanoparticles were formed by pyrolysis of hexephenyldisilane adsorbed in pores of carbon. Formation of silicon nanoparticles was observed for hexenyldisilane but not for tetraphenylsilane. Discharge capacity showed 845 $\mathrm{mAh} / \mathrm{g}$ in the first cycle but decreased greatly, later.

\section{Acknowledgements}

We are grateful to Dr. N. Yoshizawa and Dr. M. Kodama of AIST, Japan for the use of laboratory facilities and for many useful discussions, and Professor S. Hashimoto of National Institute of Technology, Gunma College for helpful discussions.

This research was supported by JSPS KAKENHI, Grant Number 16K06734.

\section{Conflicts of Interest}

The authors declare no conflicts of interest regarding the publication of this paper. 


\section{References}

[1] Zhang, W.-J. (2011) A Review of the electrochemical Performance of Alloy Anodes for Lithium-Ion Batteries. Journal of Power Sources, 196, 13-24. https://doi.org/10.1016/j.jpowsour.2010.07.020

[2] Boukamp, B.A., Lesh, G.C. and Huggins, R.A. (1981) All-Solid Lithium Electrodes with Mixed-Conductor Matrix. Journal of the Electrochemical Society, 128, 725-729. https://doi.org/10.1149/1.2127495

[3] Limthongkul, P., Jang, Y.-I., Dudney, N.J. and Chiang, Y.-M. (2003) Electrochemically-Driven Solid-State Amorphization in Lithium-Metal Anodes. Journal of Power Sources, 119-121, 604-609. https://doi.org/10.1016/s0378-7753(03)00303-3

[4] Zhang, L., Liu, X., Zhao, Q., Dou, S. Liu, H., Huang, Y. and Hu, X. (2016) Si-containing Precursors for Si-Based Anode Materials of Li-Ion Batteries: A Review. Energy Storage Materials, 4, 92-102. https://doi.org/10.1016/j.ensm.2016.01.011

[5] Zuo, X., Zhu, J., Müller-Buschbaum, P. and Cheng, Y.-J. (2017) Silicon Based Lithium-Ion Battery Anodes: A Chronicle Perspective Review. Nano Energy, 31, 113-143. https://doi.org/10.1016/j.nanoen.2016.11.013

[6] Li, P., Zhao, G., Zheng, X., Xu, X., Yao, C., Sun, W. and Dou, S.X. (2018) Recent Progress on Silicon-Based Anode Materials for Practical Lithium-Ion Battery Applications. Energy Storage Materials, 15, 422-446. https://doi.org/10.1016/j.ensm.2018.07.014

[7] Tian, H., Xin, F., Wang, X., He, W. and Han, W. (2015) High Capacity Group-IV elements (Si, Ge, Sn) Based Anodes for Lithium-Ion Batteries. Journal of Materiomics, 1, 153-169. https://doi.org/10.1016/j.jmat.2015.06.002

[8] Chen, C.K., Zhang, X.F. and Cui, Y. (2008) High Capacity Li Ion Battery Anodes Using Ge Nanowires. Nano Letters, 8, 307-309. https://doi.org/10.1021/nl0727157

[9] Goriparti, S., Miele, E., Angelis, F.D., Fabrizio, E.D., Zaccaria, R.P. and Capiglia, C. (2014) Review on Recent Progress of Nanostructured Anode Materials for Li-Ion Batteries. Journal of Power Sources, 257, 421-443. https://doi.org/10.1016/j.jpowsour.2013.11.103

[10] Song, X., Wang, X., Sun, Z., Zhang, P. and Gao, L. (2013) Recent Developments in Silicon Anode Materials for High Performance Lithium-Ion Batteries. Material Matters, 8, 111-113.

[11] Song, M.-K., Park, S., Alamgir, F.M., Cho, J. and Liu, M. (2011) Nanostructured Electrodes for Lithium-Ion and Lithium-Air Batteries: The Latest Developments, Challenges, and Perspectives. Materials Science and Engineering R, 72, 203-252. https://doi.org/10.1016/j.mser.2011.06.001

[12] Arai, K., Ota, M., Ishibashi, T., Saitoh, M., Yoshizawa, N., Imoto, K., Tanaike, O., Miyawaki, J. and Yoon, S.-H. (2015) Preparation of Silicon Nanoparticles Containing Porous Carbon Microspheres for Lithium Ion Secondary Battery Anodes. International Chemical Congress of Pacific Basin Societies 2015, 09-ENG 199. 